\title{
Development of the 12-Item Social Media Disinformation Scale and its Association With Social Media Addiction and Mental Health Related to COVID-19 in Tunisia: Survey-Based Pilot Case Study
}

Noomen Guelmami ${ }^{1,2,3}$, PhD; Maher Ben Khalifa ${ }^{4}$, MSc; Nasr Chalghaf ${ }^{2,3,5}, \mathrm{PhD}$; Jude Dzevela Kong ${ }^{6}, \mathrm{PhD}$;annoubi Amayra $^{1}, \mathrm{MSc}$; Jianhong $\mathrm{Wu}^{6}, \mathrm{PhD}$; Fairouz Azaiez ${ }^{2,3,5}, \mathrm{PhD}$; Nicola Luigi Bragazzi ${ }^{3,6}, \mathrm{MD}, \mathrm{MPH}, \mathrm{PhD}$

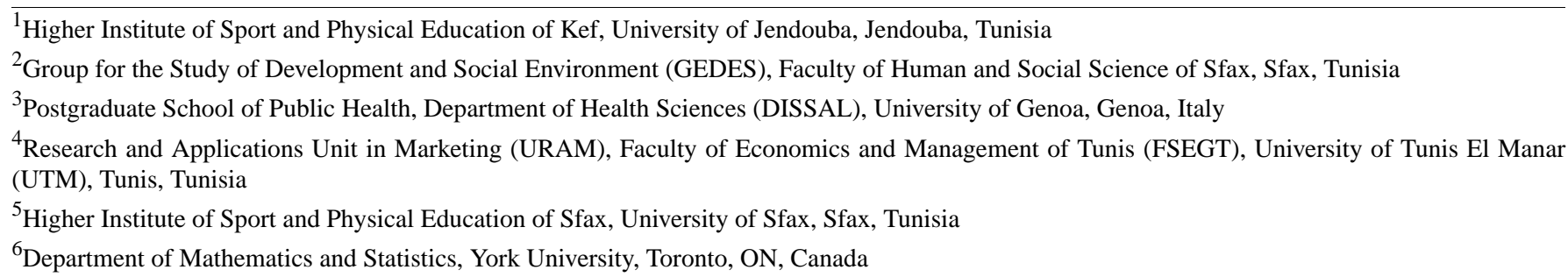

\section{Corresponding Author:}

Nicola Luigi Bragazzi, MD, MPH, PhD

Department of Mathematics and Statistics

York University

4700 Keele Street

Toronto, ON, M3J 1P3

Canada

Phone: 12818392210

Email: robertobragazzi@gmail.com

\section{Abstract}

Background: In recent years, online disinformation has increased. Fake news has been spreading about the COVID-19 pandemic. Since January 2020, the culprits and antidotes to disinformation have been digital media and social media.

Objective: Our study aimed to develop and test the psychometric properties of the 12-item Social Media Disinformation Scale (SMDS-12), which assesses the consumption, confidence, and sharing of information related to COVID-19 by social media users.

Methods: A total of 874 subjects were recruited over two phases: the exploratory phase group had a mean age of 28.39 years (SD 9.32) and the confirmatory phase group had a mean age of 32.84 years (SD 12.72). Participants completed the SMDS-12, the Internet Addiction Test, the COVID-19 Fear Scale, and the 10-item Perceived Stress Scale. The SMDS-12 was initially tested by exploratory factor analysis and was subsequently tested by confirmatory factor analysis.

Results: The test supported the three-factor structure. In addition, no items were removed from the measurement scale, with three factors explaining up to $73.72 \%$ of the total variance, and the items had a lambda factor loading ranging from 0.73 to 0.85 . Subsequently, confirmatory factor analysis confirmed the robustness of the measure by referring to a wide range of goodness-of-fit indices that met the recommended standards. The construct validity of the scale was supported by its convergent and discriminant validity. The reliability of the instrument examined by means of three internal consistency indices, and the corrected item-total correlation, demonstrated that the three dimensions of the instrument were reliable: Cronbach $\alpha$ values were $.89, .88$, and .88 for the consumption, confidence, and sharing subscales, respectively. The corrected item-total correlation ranged from 0.70 to 0.78 . The correlation of the instrument's dimensions with internet addiction and mental health factors showed positive associations.

Conclusions: The SMDS-12 can be reliably utilized to measure the credibility of social media disinformation and can be adapted to measure the credibility of disinformation in other contexts.

(JMIR Form Res 2021;5(6):e27280) doi: 10.2196/27280

\section{KEYWORDS}

COVID-19 pandemic; media disinformation; social media addiction; mental health; scale validation 


\section{Introduction}

During the COVID-19 pandemic, caused by the emerging SARS-CoV-2, people around the world have been leaning toward an excessive use of the internet [1] and social media. This is the case because, on the one hand, this activity can lower their feelings of loneliness and, on the other hand, it can provide them with information on the states of emergency in their countries and globally [2].

This pandemic is characterized by a high potential for contagion, a low availability of vaccines, an absence of specifically effective drugs, and an exponential spread, which has impacted people's lifestyles and led to feelings of insecurity [3,4], fear [5], and even community panics in several populations [6-10].

Almost everyone is interested in hearing reliable, updated information concerning the pandemic, vaccines, and anything related to COVID-19. This is because during the pandemic, in addition to seeing their usual activities restricted, people are exposed to a wide range of information, including official messages, as well as erroneous and misleading news from a range of unreliable sources $[11,12]$. The global spread of the COVID-19 pandemic has been reflected in the dissemination of misinformation on social media and conspiracy theories about its origins [13].

Indeed, since the beginning of the spread of the disease, several fake news items related to the outbreak have been shared on social networks. Examples include that the virus was caused by $5 \mathrm{G}$ cell phones, was deliberately disseminated for political or financial reasons, was a biological weapon, or was not more dangerous than influenza, with the threats being exaggerated as a way of limiting freedom [14].

Sharing false news that contains biased, emotionally charged information tends to capture more attention and interest than detached, positive, or neutral information [15]. Communication is of crucial importance in the control of outbreaks, and misinformation represents a major public health concern in that the use of social media as a means of keeping abreast of all the pandemic-related news is becoming very popular for several categories of people, due to its capacity of providing information in real time [16]. Likewise, social media can be utilized as platforms and venues for disseminating false information in times of crisis [16].

From another perspective, according to Alheneidi et al [17], besides information and communications technologies, psychosocial factors seem to play a key role. Personal negative feelings, such as loneliness, experienced during the COVID-19-induced lockdown have been shown to promote internet addiction behaviors, resulting in a significantly increased number of hours spent online. The study was conducted in two Arabic countries-Kuwait and the Kingdom of Saudi Arabia-and showed that people who experienced greater loneliness were more likely to consume pandemic-related news from social media.

Governments have been implementing behavioral strategies and nonpharmaceutical interventions (NPIs), including social and physical distancing and stay-at-home orders, to control the spread of COVID-19 and flatten the epidemic curve [18,19]. As a consequence, addiction to social media has increased, as it is the most accessible and easy-to-use means of communication and social interaction, resulting in excessive news consumption, which can lead to acute psychological distress and mental health problems, such as anxiety and depression [20].

The public health measures thus taken and enforced by governments, such as the compulsory wearing of masks, quarantine, mobility restrictions, social and physical distancing, the closures of several public places, bans on gatherings, partial curfews, and isolation of sick people, risk being compromised because of erroneous information constantly propagated on social media platforms. Indeed, Wang et al [21] have found that health-related misinformation is a very common phenomenon on social media and tends to be more prevalent than the diffusion of accurate information, in general.

As a matter of fact, significant amounts of disinformation and conspiracy theories have been disseminated through several social media platforms and consumed by users willing to learn about the COVID-19 pandemic. In general, the COVID-19 outbreak was accompanied by a large proliferation of fictitious and inaccurate information on the virus, which was spread, in particular, by social networks [22].

In a descriptive study by Cinelli et al [23] on the dissemination of COVID-19-related information on five social media platforms-Twitter, Instagram, YouTube, Reddit, and $\mathrm{Gab}$ - analyses highlighted a great amount of information about the COVID-19 outbreak disseminated on social networks, a large part of which was false information or disinformation.

COVID-19-related misinformation can bring not only high stress rates and serious mental consequences [24], but can also have a negative impact on the effectiveness of government strategies, such as the compulsory wearing of masks, confinement, and social and physical distancing. For instance, the false belief that the virus threat is being exaggerated may result in poor compliance and adherence to NPIs and, therefore, jeopardize the fight against the coronavirus. In the health field, dissemination of spurious news poses serious challenges because it can delay or prevent the delivery of effective care provisions or even threaten people's lives.

Unfortunately, many fake news items are accepted by the general population. For instance, a recent US study on COVID-19 conspiracy speculation found that over $80 \%$ of participants surveyed believed a particular conspiracy theory to be "probably" or "certainly" true [25]. In another study conducted in the United States, Uscinski et al [26] found that $29 \%$ of subjects believed that the communication on COVID-19 was biased for political reasons, in order to place then-US President Donald Trump at a disadvantage against his competitors.

If false news is accepted as true, dissemination of scientifically proven and evidence-based narratives to amend such fake news would not have a significant impact on belief in disinformation [27]. 
Although governments, public health decision makers and policy makers, and other stakeholders are suffering from the dissemination and sharing of misinformation on social media, there exists no scale that enables the quantitative assessment of the behavior of social media users in the face of misinformation related to COVID-19.

Therefore, the objective of this study was to develop and validate an ad hoc measurement tool to measure the behavior of social media users in terms of consumption, credibility, and sharing of information related to COVID-19.

\section{Methods}

\section{Ethical Declaration}

The protocol for this study received approval from the Ethics Committee of the Higher Institute of Sport and Physical Education of Kef, University of Jendouba, Jendouba, Tunisia. The study protocol also received ethical authorization from the
UNESCO (United Nations Educational, Scientific and Cultural Organization) Chair in Health Anthropology Biosphere and Healing Systems, University of Genoa, Genoa, Italy, as well as from the Higher Institute of Sport and Physical Education of Sfax, Sfax, Tunisia. The proposal was also approved by the Ethics Committee of the University of Jendouba. This study was undertaken in accordance with the ethical standards of the Declaration of Helsinki in 1964 and its subsequent amendments.

\section{Participants and Data Collection}

A total of 874 subjects, with a mean age of 30.62 years (SD 11.37), who were recruited from social media platforms over two time periods participated in this study. Participants were interviewed by means of an online questionnaire distributed via two social media platforms: Facebook and Twitter. The characteristics of the participants (ie, gender, student or employment status, academic level, and marital status) are presented in Table 1.

Table 1. Sociodemographic characteristics of the participants selected for this study.

\begin{tabular}{ll}
\hline Characteristic & Value $(\mathrm{N}=874), \mathrm{n}(\%)$ \\
\hline Gender & $415(47.5)$ \\
$\quad$ Male & $459(52.5)$ \\
$\quad$ Female & $297(34.0)$ \\
Student or employment status & $211(24.1)$ \\
Student & $94(10.8)$ \\
Public function employee & $233(26.7)$ \\
Unemployed & $39(4.5)$ \\
Private function employee & \\
Retired & $252(28.8)$ \\
Academic level & $622(71.2)$ \\
Secondary & \\
University & $446(51.0)$ \\
Marital status & $304(34.8)$ \\
Single & $124(14.2)$ \\
Married & \\
Other &
\end{tabular}

Study participants were randomly divided into two groups with the same number of individuals in each: one group participated in the exploratory phase and the other participated in the confirmatory phase.

The exploratory phase group consisted of 437 out of 874 (50.0\%) participants, of which $248(56.8 \%)$ were female and $189(43.2 \%)$ were male; the mean age of the participants in this group was 28.39 years (SD 9.32). The confirmatory phase group consisted of 437 out of $874(50.0 \%)$ participants, of which 211 $(48.3 \%)$ were female and $226(51.7 \%)$ were male; the mean age of the participants in this group was 32.84 years (SD 12.72).

\section{Instruments}

\section{Sociodemographic Questionnaire}

The sociodemographic questionnaire consisted of questions about age, gender, level of education, the city in which the participant was currently living during the COVID-19-induced restrictions, student or employment status, and marital status.

\section{Development of the 12-Item Social Media Disinformation} Scale

A thorough review of the literature showed that information consumption includes a series of behaviors and processes, such as information seeking and information encounter (ie, finding without seeking). The first is defined as the intentional acquisition of information, while information encounter 
describes how individuals come across information without deliberately seeking or retrieving news [28].

Understanding social media consumption has proven to be a very important dimension to incorporate into the measurement instrument, as it can help analyze how people may face disinformation. The literature has shown that individuals who consume disinformation make a judgment on the credibility of the message, depending on the source of the information, the story, and the context [29]. Indeed, the work of Rosnow [30] has shown that if disinformation circulates repeatedly, it will be absorbed, reinforced, and accepted as credible.

A further step in the process of information consumption is news sharing. Previous studies have reported various personal predictors of sharing misinformation, such as fear of missing out, social media fatigue, lack of skills in verifying the reliability of information, and information overload on social media. When news about a rumor is collectively shared by communities, the dissemination of that message is amplified.

Based on these theoretical findings, we operationalized the measurement of disinformation through the 12-item Social Media Disinformation Scale (SMDS-12) instrument. The first dimension of the SMDS-12 assesses the degree to which COVID-19 information is consumed from social media. The second dimension reports users' judgments about their degrees of belief, confidence, and trust in information related to COVID-19 shared on social media. The third dimension describes how one interacts with such news; in this case, sharing of information related to COVID-19.

Each dimension is made up of four items that are rated on a 5-point Likert scale, ranging from 1 (strongly disagree) to 5 (strongly agree).

Subsequently, a construct evaluation was carried out by a focus group made up of seven experts: two professionals in social networks, both administrator and content creators; two professors in human sciences; two experts in linguistics; and an expert in information and communications technology. Members of the focus group discussed the components of the items and were invited to collectively modify and validate a usable version of the instrument.

\section{The COVID-19 Fear Scale}

The Arabic-language adapted short version of the COVID-19 Fear Scale from Alyami et al was used [31]. This version has been translated and adapted into Arabic from the initial version of Ahorsu et al [32]. The scale assesses fear of COVID-19 using a one-dimensional factor tool divided into seven items, which are assessed on a 5-point Likert scale, ranging from 1 (strongly disagree) to 5 (strongly agree). Concomitant and confirmatory reliability and validity were examined on a set of Saudi participants.

The internal consistency of the Arabic version examined using Cronbach $\alpha$ was satisfactory $(\alpha=.88)$, with strong concurrent validity indicated by significant and positive correlations with the Hamilton Anxiety and Depression Scale $(r=0.6)$. Likewise, examination of the factor structure according to Alyami et al [31] was adequate (comparative fit index $[\mathrm{CFI}]=0.995$; root mean square error of approximation [RMSEA] $=0.059$; standardized root mean residual $[\mathrm{SRMR}]=0.024)$.

\section{The 10-Item Perceived Stress Scale}

An Arabic-language version of the 10-item Perceived Stress Scale (PSS-10) by Cohen et al [33], adapted by Almadi et al [34], was used to assess stress. The PSS-10 is divided into two subscales: the first assesses perceived psychological distress, while the second measures coping strategy. Scores are obtained on a 5-point Likert scale, ranging from 0 (never) to 4 (very often). The reliability and validity of the Arabic version of the PSS-10 presented a two-factor structure adequate for exploratory factor analysis, and their Cronbach $\alpha$ coefficients were .74 and .77 , respectively. In addition, the test-retest reliability had an intracorrelation coefficient of 0.90 .

For the purpose of our study, we considered only the related negative factor, which is distress; as such, the coping strategy was not taken into consideration.

\section{The Arabic Internet Addiction Test}

To measure internet addiction, we used the Arabic language-adapted scale from Hawi [35]. The Arabic version of the Internet Addiction Test (IAT) is an adapted version of the instrument originally developed by Young [36]. It consists of 20 items, each of which is scored on a 6-point Likert scale, ranging from 1 (strongly disagree) to 6 (strongly agree). The scale exhibits a unidimensional construct with robust psychometric properties: the goodness-of-fit indices demonstrated by the confirmatory factor analysis were all adequate (normed fit index $[\mathrm{NFI}]=0.96 ; \quad \mathrm{CFI}=0.98$; Tucker-Lewis index [TLI] $=0.98$; goodness-of-fit index [GFI] and adjusted goodness-of-fit index [AGFI] above the recommended thresholds of 0.90). In particular, the internal consistency examined using the classical Cronbach $\alpha$ statistical index was satisfactory $(\alpha=.92)$.

\section{Statistical Tools}

Data normality was tested by skewness and kurtosis tests during the exploratory phase, while multivariate normality was examined during the confirmatory phase. Asymmetry values greater than 7 or kurtosis values greater than 3 were judged to be non-Gaussian [37] and possessing low psychometric sensitivity [38]. In addition, the Mardia coefficient of multivariate normality was calculated during the confirmatory phase.

The exploratory analysis was carried out by unweighted least squares with a direct oblimin rotation. To assess whether the data were suitable for factor analysis, the sampling adequacy was examined by the Kaiser-Meyer-Olkin (KMO) statistic. According to the suggestions of Hair et al [39], the KMO value must be greater than 0.50 to accept the factorial solution. Furthermore, the chi-square value of the Bartlett sphericity test, which should be not significant, was calculated [40]. The factors were retained for eigenvalues greater than 1 and by examining the scree plot. In addition, an item was deleted if its factor loading was less than 0.5 [39-41]. The scale relationships have been examined through Pearson correlation tests between the SMDS-12, the COVID-19 Fear Scale, and the PSS-10. 
First-order confirmatory factor analyses were performed to examine the factor structure of the instrument. The reliability of the instrument was examined by evaluating three internal consistency indices simultaneously: McDonald $\omega$, Cronbach $\alpha$, and Gutmann $\lambda 6$. Convergent validity and discriminant validity were assessed, respectively, by calculating the average variance extracted (AVE) and comparing the square roots of the AVE values to the correlation coefficients. The relationships between instrument dimensions, internet addiction, and mental health parameters were assessed by the Pearson correlation matrix.

Descriptive statistical analyses of the factor structure were performed with SPSS for Windows, version 26 (IBM Corp), and Amos software for Windows, version 23 (IBM Corp). Internal consistency indices were calculated using JASP open source software, version 0.8.5 (JASP Team).

\section{Results}

\section{Exploratory Factor Analysis}

Table 2 shows the descriptive statistics, with means and standard deviations; the skewness and kurtosis coefficients of normality; and the lambda factor loadings. The coefficients of normality support the normality of the distributions.

The results indicate that the SMDS-12 was appropriate for proceeding with factor analysis $(\mathrm{KMO}=0.89$; Bartlett test of sphericity $=2988.98 ; d f=66 ; \mathrm{P}<.001)$. Exploratory factor analysis indicated a three-factor solution (eigenvalues were 5.45, 2.004, and 1.39 for the first, second, and third factor, respectively), explaining up to $73.72 \%$ of the total variance, with items having lambda factor loadings ranging from 0.73 to 0.85 . The first factor explained $45.42 \%$ of the total variance, the second factor explained $16.70 \%$ of the variance, and the last factor explained $11.60 \%$ of the variance. In addition, the examination of the scree plot confirms the three-factor solution; a distinct change in the slope can be seen in the plot in Multimedia Appendix 1.

Table 2. Exploratory factor analysis of the 12-item Social Media Disinformation Scale (SMDS-12) (n=437).

\begin{tabular}{lllll}
\hline SMDS-12 item No. & Mean (SD) & Skewness & Kurtosis & Lambda factor loading \\
\hline 1 & $2.94(1.25)$ & 0.02 & 2.94 & 1.25 \\
2 & $2.95(1.21)$ & 0.04 & 2.95 & 1.21 \\
3 & $2.89(1.17)$ & 0.00 & 2.89 & 1.17 \\
4 & $2.83(1.18)$ & 0.11 & 2.83 & 1.18 \\
5 & $2.76(1.09)$ & 0.10 & 2.76 & 1.09 \\
6 & $2.80(1.13)$ & 0.12 & 2.80 & 1.11 \\
7 & $2.65(1.11)$ & 0.15 & 2.65 & 1.04 \\
9 & $2.64(1.04)$ & 0.07 & 2.64 & 1.12 \\
10 & $2.45(1.12)$ & 0.31 & 2.45 & 1.12 \\
11 & $2.45(1.12)$ & 0.23 & 2.45 & 1.11 \\
\hline
\end{tabular}

\section{Confirmatory Factor Analysis}

Before proceeding with the confirmatory factor analysis, univariate and multivariate tests of normality were performed. The results indicate that the item distribution followed a
Gaussian distribution (Table 3), while the Mardia coefficient of multivariate normality indicated a value of 7.98 with a critical ratio of 4.55. These results suggest that multivariate normality was violated; on the other hand, the Mardia coefficient is sensitive to the size of the sample. 
Table 3. Confirmatory factor analysis of the 12-item Social Media Disinformation Scale (SMDS-12) ( $n=437)$.

\begin{tabular}{llllll}
\hline SMDS-12 item No. & Mean (SD) & Skewness & Critical ratio & Kurtosis & Critical ratio \\
\hline 1 & $3.16(1.16)$ & -0.1 & -0.5 & -0.7 & -3.1 \\
2 & $3.20(1.12)$ & -0.2 & -1.4 & -0.7 & -2.9 \\
3 & $3.12(1.08)$ & -0.1 & -0.7 & -0.6 & -2.5 \\
4 & $3.05(1.11)$ & 0.0 & -0.2 & -0.7 & -2.8 \\
5 & $2.88(1.13)$ & 0.0 & -0.3 & -0.8 & -3.4 \\
6 & $2.91(1.13)$ & 0.1 & -0.8 & -3.2 \\
7 & $2.80(1.08)$ & 0.1 & -0.6 & -2.7 \\
8 & $2.78(1.05)$ & 0.1 & 0.7 & -0.6 & -2.7 \\
9 & $2.43(1.14)$ & 0.27 & 0.7 & -0.85 & -4.57 \\
10 & $2.43(1.13)$ & 0.28 & 2.85 & -0.82 & -4.39 \\
11 & $2.35(1.11)$ & 0.33 & 3.02 & -0.78 & -4.21 \\
\end{tabular}

Figure 1 shows an overview of the model of the confirmatory factor analysis for the SMDS-12; following guidelines and recommendations [40,41], which suggest that a factorial weight greater than 0.71 can be considered to be excellent, we note that all items adequately contributed to the pre-established theoretical constructs. The confirmatory factor analysis results provided evidence for the three-factor structure of the SMDS-12. The factor loadings were acceptable and good (range 0.78 to 0.85 ).

Figure 1. The final confirmatory factor analysis (CFA) of the 12-item Social Media Disinformation Scale. Factor correlation coefficients are 0.24 (between consumption and sharing), 0.28 (between consumption and confidence), and 0.36 (between confidence and sharing). Factor loadings range from 0.78 to 0.85 . e1 to e12 represent the error variance for each item (I). CFA statistics: $\chi^{2}{ }_{51}=62.5, P<.001 ; \chi^{2} / \mathrm{df}=1.2 ;$ goodness-of-fit index $=0.977$; adjusted goodness-of-fit index $=0.965$; Tucker-Lewis index $=0.995$; comparative fit index $=0.996$; root mean square error of approximation $=0.023$ ( $90 \%$ CI 0-0.04); standardized root mean residual $=0.036$.

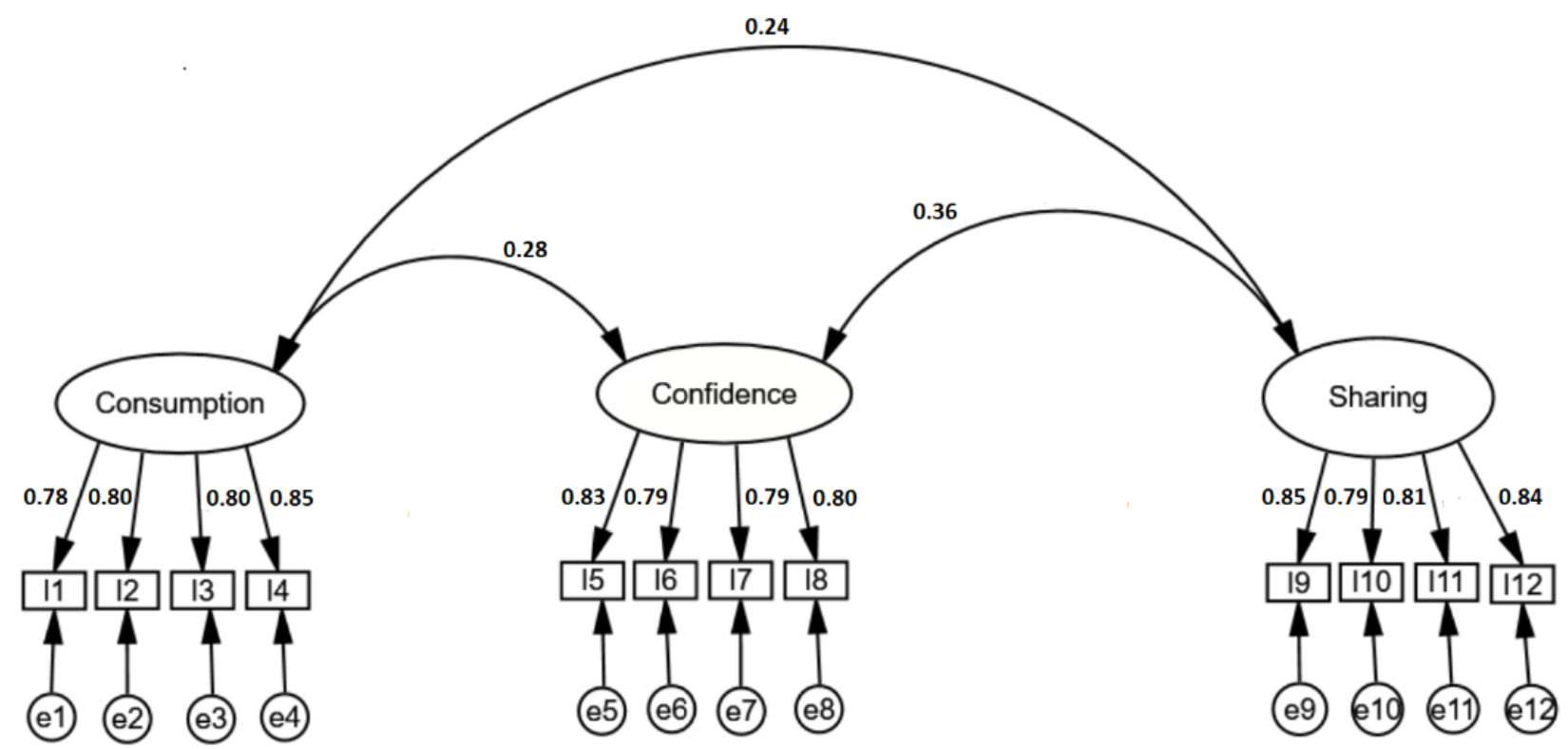

The chi-square value obtained $\left(\chi_{51}^{2}=62.5 ; P<.001\right)$ may be due to the size of the sample. However, the chi-square divided by degrees of freedom value $\left(\chi^{2} / \mathrm{df}=1.2\right)$ respects the usual recommended threshold. The values of GFI and AGFI are 0.977 and 0.965 , respectively. These two values must be greater than or equal to 0.90 . In addition, the two indices TLI and CFI tend toward 1 and respect the threshold value of 0.95 . Finally, the error indices-RMSEA $=0.023 \quad(90 \%$ CI $0-0.04)$ and SRMR $=0.036$ - show that the measurement errors are tolerable.

\section{Reliability}

The internal consistency and reliability of the three scale factors were calculated by the three indices: McDonald $\omega$, Cronbach $\alpha$, and Gutmann $\lambda 6$. Examination of the indices for the three components of the scale yielded values greater than or equal to 0.80 . This provides evidence for the internal consistency of the scale. Likewise, a good internal consistency was supported by the Cronbach $\alpha$ indices, which had values of $.89, .88$, and .88 for the consumption, confidence, and sharing subscales, respectively, as well as by the Gutmann $\lambda 6$ coefficients, which 
were greater than or equal to 0.84 . In addition, the corrected item-total correlation was calculated for each latent variable. The results show that the values were adequate, since they were located between 0.72 and 0.78 for the first component (ie, consumption), between 0.70 and 0.76 for the second component (ie, confidence), and between 0.73 and 0.76 for the last component (ie, sharing). These results confirm that the instrument has good reliability (Table 4). The internal consistency of the component is considered good if the value is equal to or greater than 0.70 [41].

Table 4. Internal consistency of the 12-item Social Media Disinformation Scale (SMDS-12).

\begin{tabular}{|c|c|c|c|c|}
\hline Latent variable and SMDS-12 item No. & Corrected item-total correlation & McDonald $\omega$ & Cronbach $\alpha$ & Gutmann $\lambda 6$ \\
\hline Consumption & & 0.89 & .89 & 0.86 \\
\hline 1 & 0.75 & & & \\
\hline 2 & 0.72 & & & \\
\hline 3 & 0.76 & & & \\
\hline 4 & 0.78 & & & \\
\hline Confidence & & 0.88 & .88 & 0.85 \\
\hline 5 & 0.76 & & & \\
\hline 6 & 0.73 & & & \\
\hline 7 & 0.70 & & & \\
\hline 8 & 0.74 & & & \\
\hline Sharing & & 0.88 & .88 & 0.85 \\
\hline 9 & 0.76 & & & \\
\hline 10 & 0.75 & & & \\
\hline 11 & 0.73 & & & \\
\hline 12 & 0.74 & & & \\
\hline
\end{tabular}

\section{Construct Validity}

\section{Convergent Validity}

The convergent validity was assessed following the Fornell-Larcker criterion [42] by the calculation of the AVE. AVE values above 0.7 are considered very satisfactory, whereas a level of 0.5 is considered acceptable. The AVE values were 0.67 for consumption, 0.64 for confidence, and 0.67 for sharing.

\section{Discriminant Validity}

Discriminant validity is ensured when the variance shared by two different latent variables is less than the variance shared by the latent variable and its indicators (ie, items). This implies that the square root of the AVE must be greater than all correlations between latent variables. The comparison of the square roots of the AVE values presented on the diagonal of the matrix (Multimedia Appendix 2) with the correlation coefficients shows that the discriminant validity of the scale was adequate.
The square roots of the AVE values for consumption, confidence, and sharing were $0.82,0.80$, and 0.81 , respectively. The comparison of each AVE value with correlation coefficients with the other constructs shows that they were of higher value.

\section{Relationship Between the Credibility of Disinformation and Mental Health During the COVID-19 Pandemic}

The correlation matrix (Table 5) provided positive, significant, and moderate associations between the dimension of consumption and internet addiction $(r=0.22)$, perceived stress $(r=0.16)$, and the fear of COVID-19 $(r=0.21)$. For the confidence subscale, a moderate correlation was demonstrated with internet addiction $(r=0.34)$, while the correlations with perceived stress and fear of COVID-19 were 0.14 and 0.23 , respectively. The sharing dimension resulted in a correlation coefficient 0.19 with internet addiction and lower coefficient values for perceived stress $(r=0.093)$ and fear of COVID-19 $(r=0.16)$. 
Table 5. Correlation matrix between the 12-item Social Media Disinformation Scale subscales and mental health parameters related to COVID-19.

\begin{tabular}{|c|c|c|c|c|c|c|}
\hline Variable & Consumption & Confidence & Sharing & Internet addiction & Perceived stress & Fear of COVID-19 \\
\hline \multicolumn{7}{|c|}{ Consumption } \\
\hline$r$ & 1 & $0.35^{\mathrm{a}}$ & $0.27^{\mathrm{a}}$ & $0.22^{\mathrm{a}}$ & $0.16^{\mathrm{a}}$ & $0.21^{\mathrm{a}}$ \\
\hline$P$ value & $-\mathrm{b}$ & $<.001$ & $<.001$ & $<.001$ & $<.001$ & $<.001$ \\
\hline \multicolumn{7}{|l|}{ Confidence } \\
\hline$r$ & $0.35^{\mathrm{a}}$ & 1 & $0.33^{\mathrm{a}}$ & $0.34^{\mathrm{a}}$ & $0.14^{\mathrm{a}}$ & $0.23^{\mathrm{a}}$ \\
\hline$P$ value & $<.001$ & - & $<.001$ & $<.001$ & $<.001$ & $<.001$ \\
\hline \multicolumn{7}{|l|}{ Sharing } \\
\hline$r$ & $0.27^{\mathrm{a}}$ & $0.33^{\mathrm{a}}$ & 1 & $0.19^{\mathrm{a}}$ & $0.093^{\mathrm{c}}$ & $0.16^{\mathrm{a}}$ \\
\hline$P$ value & $<.001$ & $<.001$ & - & $<.001$ & .014 & $<.001$ \\
\hline \multicolumn{7}{|c|}{ Internet addiction } \\
\hline$r$ & $0.22^{\mathrm{a}}$ & $0.34^{\mathrm{a}}$ & $0.19^{\mathrm{a}}$ & 1 & $0.14^{\mathrm{a}}$ & $0.21^{\mathrm{a}}$ \\
\hline$P$ value & $<.001$ & $<.001$ & $<.001$ & - & $<.001$ & $<.001$ \\
\hline \multicolumn{7}{|c|}{ Perceived stress } \\
\hline$r$ & $0.16^{\mathrm{a}}$ & $0.14^{\mathrm{a}}$ & $0.093^{\mathrm{c}}$ & $0.14^{\mathrm{a}}$ & 1 & $0.33^{\mathrm{a}}$ \\
\hline$P$ value & $<.001$ & $<.001$ & .014 & $<.001$ & - & $<.001$ \\
\hline \multicolumn{7}{|c|}{ Fear of COVID-19 } \\
\hline$r$ & $0.21^{\mathrm{a}}$ & $0.23^{\mathrm{a}}$ & $0.16^{\mathrm{a}}$ & $0.21^{\mathrm{a}}$ & $0.33^{\mathrm{a}}$ & 1 \\
\hline$P$ value & $<.001$ & $<.001$ & $<.001$ & $<.001$ & $<.001$ & - \\
\hline
\end{tabular}

${ }^{\mathrm{a}}$ The correlation is significant at a significance level of .01 (two-tailed).

${ }^{\mathrm{b}}$ Not applicable.

${ }^{\mathrm{c}}$ The correlation is significant at a significance level of .05 (two-tailed).

\section{Discussion}

\section{Principal Findings}

The objective of this study was to develop and test the psychometric properties of the SMDS-12 measurement scale to assess consumption, confidence, and sharing of information related to COVID-19 by social media users. The 12 -item scale was initially tested through exploratory factor analysis.

The test supported the three-factor structure; in addition, no items were removed from the measurement scale. Subsequently, confirmatory factor analysis confirmed the robustness of the measurement tool. The results also supported the construct validity of the scale by its convergent and discriminant validity, both of which were adequate. The reliability of the instrument examined by means of three internal consistency indices and the corrected item-total correlation demonstrated that the three dimensions of the instrument are reliable.

The correlation between the three dimensions of the instrument with the internet addiction scale and mental health factors showed positive associations, which lay in a range from small, for the relationship of the sharing dimension with stress, to moderate, for the association of the other two factors with internet addiction, perceived stress, and fear of COVID-19.
Regarding the links between the consumption of disinformation and internet addiction, similar results have been reported by Priego-Parra et al [43]. The authors found that internet addiction and overexposure to rapidly spreading disinformation are associated with anxiety and depression. In addition, internet addiction resulting in obtaining information about COVID-19 has increased stress and anxiety levels.

Furthermore, in other studies of COVID-19 related to disinformation spread on social media [44-48], aimed at identifying the prevalence and factors associated with the concept, disinformation was shown to be linked to demographic variables, such as age, gender, and academic level. Moreover, consistent with our findings, misinformation beliefs were significantly associated with fear of COVID-19 in addition to other variables, such as lower levels of health education, trust in government, and confidence in science.

During the COVID-19 pandemic, internet addiction and the use of social media in particular have increased significantly [44-48]. Also, time spent on the internet was associated with sharing misinformation related to the context of the illness [44-49].

Moreover, some studies [50-52] examined the association between social media and mental health linked to the COVID-19 pandemic. The results showed that social media use was linked to depression, and excessive social media use led to mental health issues. 
Our findings are also in line with a pilot study by Zhong et al [20], which examined the possible association between social media use and the mental health toll linked to the COVID-19 pandemic in China. This study found that social media use was linked to both depression and secondary trauma, which also predicted a change in health behavior.

On the contrary, in a cross-sectional survey by Agley and Xiao [14], COVID-19-related information sharing behaviors were clustered, and four belief profiles emerged from the analysis. A total of $70 \%$ of the subjects surveyed believed in scientifically accepted theories (ie, zoonotic origin of the outbreak) and not in conspiratorial theories. Other profiles disagreed with the zoonotic explanation, and instead believed in misinformation, although to varying degrees. Briefly, trust in science was a strong and significant predictor of news sharing behavior.

Regarding the acquisition of disinformation and the subsequent sharing of this information, Chua and Banerjee [53] showed that gullible users had a greater propensity to share health rumors online. For that reason, $\mathrm{Li}$ and Sakamoto [54] suggested that exposing individuals to collective opinion measures may reduce the tendency to share false health messages. To explain the mechanism, the theory of cultural attraction can be utilized. Indeed, this theory postulates that the spread of rumors results from psychological pull factors. The reasons for the propagation of this false information are mainly due to the recruitment of cognitive pull factors that are likely to increase social interactions [55]. Indeed, on these platforms, content creators produce their works with a strong psychological appeal to encourage users to react to them and increase their audiences.

This highlights the need for much more research into the cultural, psychological, and social characteristics of users who trust and disseminate this content on social media. In particular, it is crucial to better understand the roles of thinking and belief systems. For example, they should also be explored in empirical studies, in particular, relying on mathematical models based on big data and artificial intelligence. This would be of paramount importance, given the potential impact of COVID-19-related misinformation on the public health measures implemented to curb the pandemic [56-61].

\section{Conclusions and Recommendations}

The results of this study provided a first demonstration for assessing behaviors related to use, consumption, and sharing of information related to COVID-19 on social media. The SMDS-12 exhibited acceptable psychometric properties and can be utilized in Tunisia and other Arabic countries to explore user engagement with social media, credibility of information, and interaction with information in terms of sharing. Furthermore, the instrument could be translated, culturally validated, and utilized by other scholars from other countries.

\section{Limitations of the Study}

The main limitation of this study is the lack of concurrent validity testing of the instrument with similar instruments. In addition, the instrument has only been tested on a single population living in a single country. Also, the study was observational and not interventional; it did not investigate ways that could reduce credibility and counteract the sharing of rumors and misinformation. Another limitation relates to the study population, as the data were collected from a group of Tunisian social media users. Although we have confirmed the validity and reliability of the measurement instrument for these participants, a certain specificity linked to the cultural context does not allow for the generalization of the results.

\section{Acknowledgments}

This research was funded by Canada's International Development Research Centre (IDRC) (grant 109559-001).

\section{Conflicts of Interest}

None declared.

\section{Multimedia Appendix 1}

Scree plot for the principal component analysis of the 12-item Social Media Disinformation Scale (SMDS-12). [PNG File, 16 KB-Multimedia Appendix 1]

\section{Multimedia Appendix 2}

Discriminant validity of the 12-item Social Media Disinformation Scale (SMDS-12) subscales. [DOCX File, 13 KB-Multimedia Appendix 2]

\section{References}

1. Shen TS, Chen AZ, Bovonratwet P, Shen CL, Su EP. COVID-19-related internet search patterns among people in the United States: Exploratory analysis. J Med Internet Res 2020 Nov 23;22(11):e22407 [FREE Full text] [doi: 10.2196/22407] [Medline: $\underline{33147163}$ ]

2. Farooq A, Laato S, Islam AKMN. Impact of online information on self-isolation intention during the COVID-19 pandemic: Cross-sectional study. J Med Internet Res 2020 May 06;22(5):e19128 [FREE Full text] [doi: 10.2196/19128] [Medline: $\underline{32330115}$ 
3. Molteni F, Ladini R, Biolcati F, Chiesi AM, Dotti Sani GM, Guglielmi S, et al. Searching for comfort in religion: Insecurity and religious behaviour during the COVID-19 pandemic in Italy. Eur Societies 2020 Oct 29;23(sup1):S704-S720. [doi: $10.1080 / 14616696.2020 .1836383]$

4. Wilson J, Lee J, Fitzgerald HN, Oosterhoff B, Sevi B, Shook NJ. Job insecurity and financial concern during the COVID-19 pandemic are associated with worse mental health. J Occup Environ Med 2020 Sep;62(9):686-691. [doi: 10.1097/JOM.0000000000001962] [Medline: 32890205]

5. Shah K, Kamrai D, Mekala H, Mann B, Desai K, Patel RS. Focus on mental health during the coronavirus (COVID-19) pandemic: Applying learnings from the past outbreaks. Cureus 2020 Mar 25;12(3):e7405 [FREE Full text] [doi: 10.7759/cureus.7405] [Medline: $\underline{32337131]}$

6. Zheng D, Luo Q, Ritchie BW. Afraid to travel after COVID-19? Self-protection, coping and resilience against pandemic 'travel fear'. Tour Manag 2021 Apr;83:104261. [doi: 10.1016/j.tourman.2020.104261]

7. Malta M, Rimoin AW, Strathdee SA. The coronavirus 2019-nCoV epidemic: Is hindsight 20/20? EClinicalMedicine 2020 Mar;20:100289 [FREE Full text] [doi: 10.1016/j.eclinm.2020.100289] [Medline: 32154505]

8. Nicomedes CJC, Avila RMA. An analysis on the panic during COVID-19 pandemic through an online form. J Affect Disord 2020 Nov 01;276:14-22 [FREE Full text] [doi: 10.1016/j.jad.2020.06.046] [Medline: 32697692]

9. Islam MS, Ferdous MZ, Potenza MN. Panic and generalized anxiety during the COVID-19 pandemic among Bangladeshi people: An online pilot survey early in the outbreak. J Affect Disord 2020 Nov 01;276:30-37 [FREE Full text] [doi: 10.1016/j.jad.2020.06.049] [Medline: 32697713]

10. Saurabh K, Ranjan S. Compliance and psychological impact of quarantine in children and adolescents due to Covid-19 pandemic. Indian J Pediatr 2020 Jul;87(7):532-536 [ FREE Full text] [doi: 10.1007/s12098-020-03347-3] [Medline: 32472347]

11. Usher K, Jackson D, Durkin J, Gyamfi N, Bhullar N. Pandemic-related behaviours and psychological outcomes: A rapid literature review to explain COVID-19 behaviours. Int J Ment Health Nurs 2020 Dec;29(6):1018-1034. [doi:

10.1111/inm.12790] [Medline: 32860475]

12. Yang KC, Torres-Lugo C, Menczer F. Prevalence of low-credibility information on Twitter during the COVID-19 outbreak. In: Proceedings of the 14th International AAAI Conference on Web and Social Media Workshop. 2020 Presented at: 14th International AAAI Conference on Web and Social Media Workshop; June 8-11, 2020; Atlanta, GA p. 1-4 URL: http:/ /workshop-proceedings.icwsm.org/pdf/2020 16.pdf [doi: 10.36190/2020.16]

13. Pickles K, Cvejic E, Nickel B, Copp T, Bonner C, Leask J, et al. COVID-19 misinformation trends in Australia: Prospective longitudinal national survey. J Med Internet Res 2021 Jan 07;23(1):e23805 [FREE Full text] [doi: 10.2196/23805] [Medline: 33302250]

14. Agley J, Xiao Y. Misinformation about COVID-19: Evidence for differential latent profiles and a strong association with trust in science. BMC Public Health 2021 Jan 07;21(1):89 [FREE Full text] [doi: 10.1186/s12889-020-10103-x] [Medline: 33413219]

15. Grabowski A, Wojciszke B, Bromer P. Ambivalence of attitudes towards people with whom the contact is closed or continued. Pol Psychol Bull 2005;36(2):99-107 [FREE Full text]

16. Islam AN, Laato S, Talukder S, Sutinen E. Misinformation sharing and social media fatigue during COVID-19: An affordance and cognitive load perspective. Technol Forecast Soc Change 2020 Oct;159:120201 [FREE Full text] [doi: 10.1016/j.techfore.2020.120201] [Medline: 32834137]

17. Alheneidi H, AlSumait L, AlSumait D, Smith AP. Loneliness and problematic internet use during COVID-19 lock-down. Behav Sci (Basel) 2021 Jan 06;11(1):5 [FREE Full text] [doi: 10.3390/bs11010005] [Medline: 33418914]

18. Cook J, Newberger N, Smalling S. The spread of social distancing. Econ Lett 2020 Nov; 196:109511 [FREE Full text] [doi: 10.1016/j.econlet.2020.109511] [Medline: 32904988]

19. Jay J, Bor J, Nsoesie EO, Lipson SK, Jones DK, Galea S, et al. Neighbourhood income and physical distancing during the COVID-19 pandemic in the United States. Nat Hum Behav 2020 Dec;4(12):1294-1302 [FREE Full text] [doi: 10.1038/s41562-020-00998-2] [Medline: 33144713]

20. Zhong B, Huang Y, Liu Q. Mental health toll from the coronavirus: Social media usage reveals Wuhan residents' depression and secondary trauma in the COVID-19 outbreak. Comput Human Behav 2021 Jan;114:106524 [FREE Full text] [doi: 10.1016/j.chb.2020.106524] [Medline: 32836728]

21. Wang Y, McKee M, Torbica A, Stuckler D. Systematic literature review on the spread of health-related misinformation on social media. Soc Sci Med 2019 Nov;240:112552 [FREE Full text] [doi: 10.1016/j.socscimed.2019.112552] [Medline: $\underline{31561111]}$

22. Berriche M, Altay S. Internet users engage more with phatic posts than with health misinformation on Facebook. Palgrave Commun 2020 Apr 28;6(1):1-9. [doi: 10.1057/s41599-020-0452-1]

23. Cinelli M, Quattrociocchi W, Galeazzi A, Valensise CM, Brugnoli E, Schmidt AL, et al. The COVID-19 social media infodemic. Sci Rep 2020 Oct 06;10(1):16598 [FREE Full text] [doi: 10.1038/s41598-020-73510-5] [Medline: 33024152]

24. Cuan-Baltazar J, Muñoz-Perez MJ, Robledo-Vega C, Pérez-Zepeda MF, Soto-Vega E. Misinformation of COVID-19 on the internet: Infodemiology study. JMIR Public Health Surveill 2020 Apr 09;6(2):e18444 [FREE Full text] [doi:

10.2196/18444] [Medline: 32250960] 
25. Miller JM. Do COVID-19 conspiracy theory beliefs form a monological belief system? Can J Polit Sci 2020 May 21;53(2):319-326. [doi: 10.1017/s0008423920000517]

26. Uscinski JE, Enders AM, Klofstad C, Seelig M, Funchion J, Everett C, et al. Why do people believe COVID-19 conspiracy theories? Misinf Rev 2020 Apr 28;1(3):1-12 [FREE Full text] [doi: 10.37016/mr-2020-015]

27. Agley J, Xiao Y, Thompson EE, Golzarri-Arroyo L. COVID-19 misinformation prophylaxis: Protocol for a randomized trial of a brief informational intervention. JMIR Res Protoc 2020 Dec 07;9(12):e24383 [FREE Full text] [doi: 10.2196/24383] [Medline: 33175694]

28. Lewis M. Addiction and the brain: Development, not disease. Neuroethics 2017;10(1):7-18 [FREE Full text] [doi: 10.1007/s12152-016-9293-4] [Medline: 28725282]

29. Moscadelli A, Albora G, Biamonte MA, Giorgetti D, Innocenzio M, Paoli S, et al. Fake news and Covid-19 in Italy: Results of a quantitative observational study. Int J Environ Res Public Health 2020 Aug 12;17(16):5850 [FREE Full text] [doi: 10.3390/ijerph17165850] [Medline: 32806772]

30. Rosnow RL. Inside rumor: A personal journey. Am Psychol 1991;46(5):484-496. [doi: 10.1037/0003-066x.46.5.484]

31. Alyami M, Henning M, Krägeloh U, Alyami H. Psychometric evaluation of the Arabic version of the Fear of COVID-19 Scale. Int J Ment Health Addict 2020 May 16:1-14 [FREE Full text] [doi: 10.1007/s11469-020-00316-x] [Medline: 32427217]

32. Ahorsu DK, Lin C, Imani V, Saffari M, Griffiths MD, Pakpour AH. The Fear of COVID-19 Scale: Development and initial validation. Int J Ment Health Addict 2020 Mar 27:1-9. [doi: 10.1007/s11469-020-00270-8]

33. Cohen S. Perceived stress in a probability sample of the United States. In: Spacapan S, Oskamp S, editors. The Social Psychology of Health: The Claremont Symposium on Applied Social Psychology. Claremont, CA: SAGE Publications Inc; 1988:31-67.

34. Almadi T, Cathers I, Hamdan Mansour AM, Chow CM. An Arabic version of the perceived stress scale: Translation and validation study. Int J Nurs Stud 2012 Jan;49(1):84-89. [doi: 10.1016/j.ijnurstu.2011.07.012] [Medline: 21851941]

35. Hawi NS. Arabic validation of the internet addiction test. Cyberpsychol Behav Soc Netw 2013 Mar;16(3):200-204. [doi: 10.1089/cyber.2012.0426] [Medline: 23441685]

36. Young KS. Internet Addiction Test (IAT). Wood Dale, IL: Stoelting; 2017. URL: https://www.stoeltingco.com/media/ wysiwyg/IAT web sample.pdf [accessed 2021-05-06]

37. Finney SJ, DiStefano C. Nonnormal and categorical data in structural equation modeling. In: Hancock GR, Mueller RO, editors. Structural Equation Modeling: A Second Course. 2nd edition. Charlotte, NC: Information Age Publishing Inc; 2013.

38. Tabachnick BG, Fidell LS. Using Multivariate Statistics. 5th edition. Boston, MA: Pearson Education Inc; 2007.

39. Hair JF, Anderson RE, Tatham RL, Black WC. Multivariate Data Analysis. 4th edition. Upper Saddle River, NJ: Prentice-Hall Inc; 1995.

40. Westfall PH, Henning KSS. Understanding Advanced Statistical Methods. Boca Raton, FL: CRC Press; 2013.

41. Ware JE, Gandek B. Methods for testing data quality, scaling assumptions, and reliability. J Clin Epidemiol 1998 Nov;51(11):945-952. [doi: 10.1016/s0895-4356(98)00085-7]

42. Fornell C, Larcker DF. Evaluating structural equation models with unobservable variables and measurement error. J Mark Res 1981 Feb;18(1):39-50. [doi: 10.2307/3151312]

43. Priego-Parra BA, Triana-Romero A, Pinto-Galvez SM, Duran-Ramos C, Salas-Nolasco O, Manriquez Reyes M, et al. Anxiety, depression, attitudes, and internet addiction during the initial phase of the 2019 coronavirus disease (COVID-19) epidemic: A cross-sectional study in México. medRxiv. Preprint posted online on May 15, 2020. [FREE Full text] [doi: 10.1101/2020.05.10.20095844]

44. Maroco J, Maroco AL, Campos JADB. Student's academic efficacy or inefficacy? An example on how to evaluate the psychometric properties of a measuring instrument and evaluate the effects of item wording. Open J Stat 2014;04(06):484-493. [doi: 10.4236/ojs.2014.46046]

45. Zhen L, Nan Y, Pham B. College students coping with COVID-19: Stress-buffering effects of self-disclosure on social media and parental support. Commun Res Rep 2021 Jan 08;38(1):23-31. [doi: 10.1080/08824096.2020.1870445]

46. Tsao SF, Chen H, Tisseverasinghe T, Yang Y, Li L, Butt ZA. What social media told us in the time of COVID-19: A scoping review. Lancet Digit Health 2021 Mar;3(3):e175-e194 [FREE Full text] [doi: 10.1016/S2589-7500(20)30315-0] [Medline: 33518503]

47. Onuora C, Torti Obasi N, Ezeah GH, Gever VC. Effect of dramatized health messages: Modelling predictors of the impact of COVID-19 YouTube animated cartoons on health behaviour of social media users in Nigeria. Int Sociol 2020 Oct 26;36(1):124-140. [doi: 10.1177/0268580920961333]

48. Ferrara E. \#COVID-19 on Twitter: Bots, conspiracies, and social media activism. ArXiv. Preprint posted online on April 20, 2020. [FREE Full text]

49. Apuke OD, Omar B. Fake news and COVID-19: Modelling the predictors of fake news sharing among social media users. Telematics Inform 2021 Jan;56:101475. [doi: 10.1016/j.tele.2020.101475]

50. He Q, Fan B, Xie B, Liao Y, Han X, Chen Y, et al. Mental health conditions among the general population, healthcare workers and quarantined population during the coronavirus disease 2019 (COVID-19) pandemic. Psychol Health Med 2020 Dec 30:1-13. [doi: 10.1080/13548506.2020.1867320] [Medline: 33378219] 
51. Su Z, McDonnell D, Wen J, Kozak M, Abbas J, Šegalo S, et al. Mental health consequences of COVID-19 media coverage: The need for effective crisis communication practices. Global Health 2021 Jan 05;17(1):4 [FREE Full text] [doi: 10.1186/s12992-020-00654-4] [Medline: 33402169]

52. McCracken LM, Badinlou F, Buhrman M, Brocki KC. The role of psychological flexibility in the context of COVID-19: Associations with depression, anxiety, and insomnia. J Contextual Behav Sci 2021 Jan;19:28-35. [doi:

10.1016/j.jcbs.2020.11.003]

53. Chua AY, Banerjee S. To share or not to share: The role of epistemic belief in online health rumors. Int J Med Inform 2017 Dec;108:36-41. [doi: 10.1016/j.ijmedinf.2017.08.010] [Medline: 29132629]

54. Li H, Sakamoto Y. Re-tweet count matters: Social influences on sharing of disaster-related tweets. J Homel Secur Emerg Manag 2015;12(3):737-761. [doi: 10.1515/jhsem-2014-0081]

55. Acerbi A. Cognitive attraction and online misinformation. Palgrave Commun 2019 Feb 12;5(1):1-7. [doi: 10.1057/s41599-019-0224-y]

56. Zheng GW, Siddik AB, Yan C, Masukujjaman M. Official and unofficial media information and the public panic during the COVID-19 pandemic in China: An empirical analysis. Rev Argent Clínica Psicológica 2020;29(5):1538-1551 [FREE Full text] [doi: $10.24205 / 03276716.2020 .1151]$

57. Harris G. Combating the spread of health misinformation on social media. Br J Healthc Manag 2021 Jan 02;27(1):40-42. [doi: 10.12968/bjhc.2020.0128]

58. Heydari ST, Zarei L, Sadati AK, Moradi N, Akbari M, Mehralian G, et al. The effect of risk communication on preventive and protective behaviours during the COVID-19 outbreak: Mediating role of risk perception. BMC Public Health 2021 Jan 06;21(1):54 [FREE Full text] [doi: 10.1186/s12889-020-10125-5] [Medline: 33407302]

59. Nazione S, Perrault E, Pace K. Impact of information exposure on perceived risk, efficacy, and preventative behaviors at the beginning of the COVID-19 pandemic in the United States. Health Commun 2021 Jan;36(1):23-31. [doi: 10.1080/10410236.2020.1847446] [Medline: 33183090]

60. Painter M, Qiu T. Political beliefs affect compliance with COVID-19 social distancing orders. J Econ Behav Organ 2021:1 (forthcoming). [doi: 10.2139/ssrn.3569098]

61. Ienca M, Vayena E. On the responsible use of digital data to tackle the COVID-19 pandemic. Nat Med 2020 Apr;26(4):463-464 [FREE Full text] [doi: 10.1038/s41591-020-0832-5] [Medline: $\underline{\text { 32284619] }}$

\section{Abbreviations}

AGFI: adjusted goodness-of-fit index

AVE: average variance extracted

CFI: comparative fit index

GFI: goodness-of-fit index

IAT: Internet Addiction Test

IDRC: International Development Research Centre

KMO: Kaiser-Meyer-Olkin

NFI: normed fit index

NPI: nonpharmaceutical intervention

PSS-10: 10 -item Perceived Stress Scale

RMSEA: root mean square error of approximation

SMDS-12: 12 -item Social Media Disinformation Scale

SRMR: standardized root mean residual

TLI: Tucker-Lewis index

UNESCO: United Nations Educational, Scientific and Cultural Organization

Edited by G Eysenbach; submitted 19.01.21; peer-reviewed by H Dai, R Treskes, SL Lee; comments to author 16.02.21; revised version
received 03.03.21; accepted 03.05.21; published 09.06.21
Please cite as:
Guelmami N, Ben Khalifa M, Chalghaf N, Kong JD, Amayra T, Wu J, Azaiez F, Bragazzi NL
Development of the 12-Item Social Media Disinformation Scale and its Association With Social Media Addiction and Mental Health
Related to COVID-19 in Tunisia: Survey-Based Pilot Case Study
JMIR Form Res $2021 ; 5(6):$ :e27280
URL: $\underline{\text { https://formative.jmir.org/2021/6/e27280 }}$
doi: $\underline{10.2196 / 27280}$
PMID: $\underline{34021742}$


(CNoomen Guelmami, Maher Ben Khalifa, Nasr Chalghaf, Jude Dzevela Kong, Tannoubi Amayra, Jianhong Wu, Fairouz Azaiez, Nicola Luigi Bragazzi. Originally published in JMIR Formative Research (https://formative.jmir.org), 09.06.2021. This is an open-access article distributed under the terms of the Creative Commons Attribution License (https://creativecommons.org/licenses/by/4.0/), which permits unrestricted use, distribution, and reproduction in any medium, provided the original work, first published in JMIR Formative Research, is properly cited. The complete bibliographic information, a link to the original publication on https://formative.jmir.org, as well as this copyright and license information must be included. 